\title{
Fisetin Ameliorates the Inflammation and Oxidative Stress in Lipopolysaccharide-Induced Endometritis
}

\author{
Kangfeng Jiang ${ }^{1,2, *}$ \\ Jing Yang ${ }^{3, *}$ \\ Guanhong Xue ${ }^{1, *}$ \\ Ailing Dai ${ }^{4}$ \\ Haichong Wu iD ${ }^{\prime}$ \\ 'Department of Veterinary Medicine, \\ College of Animal Sciences, Zhejiang \\ University, Hangzhou, 310058, Zhejiang, \\ People's Republic of China; ${ }^{2}$ Department \\ of Clinical Veterinary Medicine, College \\ of Veterinary Medicine, Yunnan \\ Agricultural University, Kunming, Yunnan, \\ 65020I, People's Republic of China; \\ ${ }^{3}$ State Key Laboratory of Agricultural \\ Microbiology, College of Veterinary \\ Medicine, Huazhong Agricultural \\ University, Wuhan, Hubei, 430070 , \\ People's Republic of China; ${ }^{4}$ College of \\ Life Sciences of Longyan University, \\ Longyan, 3640 I2, Fujian, People's \\ Republic of China
}

*These authors contributed equally to this work

\begin{abstract}
Purpose: Fisetin is a natural flavone of polyphenol, which widely exists in many fruits and vegetables and has many pharmacological activities. However, the mechanism involved remains largely unknown. Here, we investigate the mechanisms of fisetin on the inflammatory response and oxidative stress in LPS-induced endometritis model and bovine endometrial epithelial cell line (BEND).
\end{abstract}

Methods: The function of fisetin was analyzed by network pharmacology. Effects of increasing doses of fisetin on inflammation and oxidative stress are studied in BALB/c mice with LPS-induced endometritis. The underlying mechanisms of antioxidant activity of fisetin were further explored in LPS-stimulated BEND cells.

Results: The results showed that fisetin significantly alleviated LPS-induced inflammatory injury and oxidative stress both in vivo and in vitro. Further studies found that fisetin greatly inhibited the LPS stimulated TLR4 expression and nuclear translocation of nuclear factor- $\kappa \mathrm{B}$ $(\mathrm{NF}-\kappa \mathrm{B})$, thus reducing the pro-inflammatory mediators secretion. Silencing TLR4 reduced LPS-induced inflammatory responses. Moreover, we observed that fisetin evidently decreased ROS production but activated Nrf2/HO-1 pathway in LPS-stimulated BEND cells. To further explore the role of Nrf2 in fisetin-induced HO-1 protein expression, the specific siRNA was used to silence Nrf2 expression. Silencing Nrf2 abrogated the inhibitory effects of fisetin on LPS-induced pro-inflammatory cytokines TNF- $\alpha$, IL- $1 \beta$ secretion, NADPH oxidase-4 (Nox4) and ROS production.

Conclusion: In conclusion, fisetin effectively protected against LPS-induced oxidative stress and inflammatory responses which may be closely correlated to inhibition of TLR4mediated ROS/NF- $\mathrm{KB}$ and activation of the Nrf2/HO-1 pathway.

Keywords: fisetin, endometritis, inflammation, oxidative stress, TLR4/Nrf2

\section{Introduction}

Endometritis is one of the most common reproductive diseases caused by bacteria in the cattle industry all over the world. It leads to significant economic losses due to the decrease of their reproductive performance and subsequent low milk yield. ${ }^{1}$ Endometritis is mainly caused by the invasion of pathogenic microorganism, its characteristic is rotten, wet, uterine secretions of red brown, accompanied by fever, dehydration, depression. ${ }^{2}$ Piras et al reported that $E$. coli was one of the most frequent pathogenic bacteria involved in uterine diseases. $^{3}$ It is well know that Lipopolysaccharide (LPS) is an essential constituent of the outer membrane of Gramnegative bacteria. ${ }^{4}$ LPS, a Toll-like receptor 4 (TLR4) receptor agonist, induces the
Correspondence: Haichong Wu

Tel +86 57l-8898209l

Email haichongwu@zju.edu.cn 
release of pro-inflammatory cytokines including interleukin$1 \beta$ (IL-1 $\beta$ ) and tumor necrosis factor- $\alpha$ (TNF- $\alpha$ ) during the inflammatory response. ${ }^{5}$ TLR4 as a member of pattern recognition receptors participates in recognizing exogenous pathogen-associated molecular patterns and endogenous ligands. ${ }^{6}$ Accumulating evidence suggests that during the LPS stimulation, the activation of TLR4-mediated NF- $\mathrm{BB}$ signaling pathway, with the subsequent release of proinflammatory cytokines. ${ }^{7,8} \mathrm{NF}-\kappa \mathrm{B}$ is involved in the activation of a large number of genes in response to infections, inflammation, and other stress states that require rapid reprogramming of gene expression. ${ }^{9}$

Oxidative stress is a complication of reactive oxygen species (ROS) producing more than antioxidant enzymes. ${ }^{10}$ The anti-oxidative enzymes, such as heme oxygenase (HO)1 , are mediated by nuclear factor-erythroid 2-related factor 2 (Nrf2). ${ }^{11}$ ROS are served as secondary messengers that amplify inflammatory response by up-regulating kinase cascades. $^{7}$ NADPH oxidases (Noxs, for example Nox4) are enzymes acting to generate reactive oxygen species (ROS). Numerous studies have indicated a critical role for ROS induction in multiple signaling pathways, including $\mathrm{NF}-\kappa \mathrm{B}$ pathway, which is one of the major signaling conduits mediating inflammation. ${ }^{12,13}$

Fisetin $\left(3,3^{\prime}, 4^{\prime}, 7\right.$-tetrahydroxyflavone, shown in Figure 1A), is a polyphenol and naturally occurring flavonoid that is commonly found in many fruits and vegetables including persimmons, mangoes, grapes, apples, strawberries, peaches, cucumbers, onions and tomatoes. ${ }^{14,15}$ It has a wide range of pharmacological functions, including antiinflammatory, anti-oxidant, and anti-tumor activities. ${ }^{16-18}$ Previous studies have also reported that fisetin can inhibit LPS-induced inflammatory response. ${ }^{14,19}$ However, the anti-inflammatory and anti-oxidant effects of fisetin in

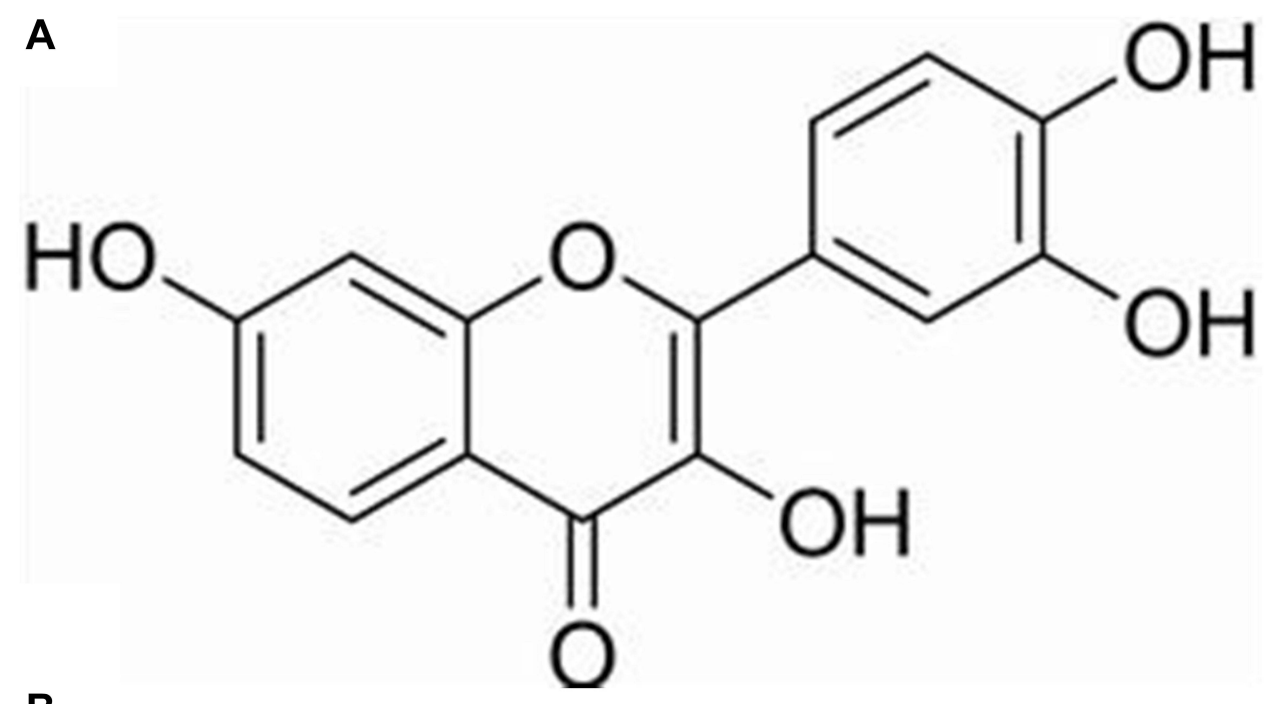

B

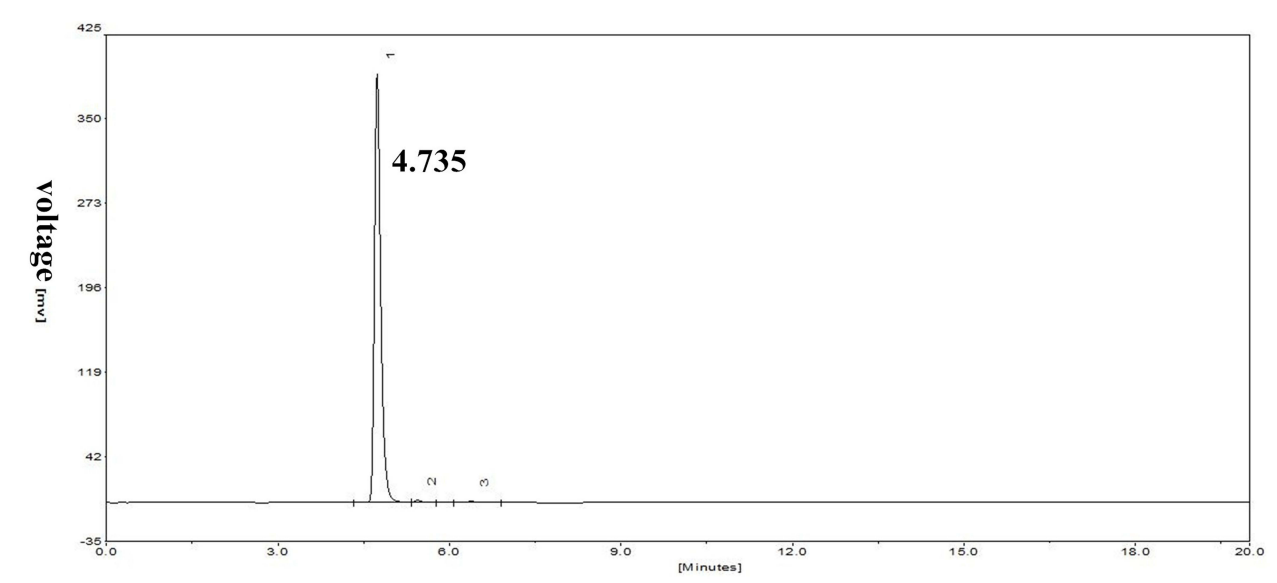

Figure I (A) The chemical structure of fisetin. (B) HPLC chromatogram of fisetin. 
LPS-induced endometritis remains unclear. Moreover, endometrial epithelial cells are the first line of defense to protect the uterus from pathogenic bacteria. ${ }^{20}$ Therefore, in the present study, LPS-induced endometritis in mice and bovine endometrial epithelial cell line in vitro were performed to determine the anti-inflammatory and antioxidant molecular mechanisms of fisetin.

\section{Materials and Methods Network Pharmacology Analysis}

The druggability of fisetin was assessed by Traditional Chinese Medicine Systems Pharmacology database (TCMSP, https://tcmspw.com/), and the potential targets of fisetin were identified using the SwissTarget Prediction (http://www.swisstargetprediction.ch/). Additionally, gene ontology (GO) and Kyoto Encyclopedia of Genes and Genomes (KEGG) analysis were performed using Metascape (https://metascape. org/). Drug-target-pathway networks were constructed using Cytoscape to give a visual view.

\section{Animals and Ethical Statement}

Female BALB/c mice (6-8 weeks old, 20-22 $\mathrm{g}$ weight), were purchased from Animal experiment center of Huazhong Agricultural University (Wuhan, China). The mice were housed in plastic cages at 24 $\pm 1^{\circ} \mathrm{C}$ and kept on a $12 \mathrm{~h}$ dark-light cycle for one week before the study. This experiment was proceeded according to the guidelines of the Huazhong Agricultural University Animal Care Committee and the care and use of Laboratory Animals published by the US National Institutes of Health. Randomization was used to assign samples to the experimental groups and to collect and process data. The experiments were performed by investigators blinded to the treatment groups.

\section{Study Design}

Mice were randomly divided into five groups $(n=10)$, consisting of control group, fisetin $(25$, and $50 \mathrm{mg} / \mathrm{kg}$ ) + LPS groups, LPS group, and fisetin (50 mg/kg) group. Fisetin was solubilized by dimethyl sulfoxide (DMSO, $<0.1 \%$, Sigma, USA) to obtain final concentrations of 25 , and $50 \mathrm{mg} / \mathrm{kg}$. The method for constructing mouse endometritis model was carry out as previously described. $^{21}$ In brief, mice were intramuscularly injected with fisetin twice every 12 $\mathrm{h}$. After $2 \mathrm{~h}$ injection, the mouse uterus was perfused with LPS $(1 \mathrm{mg} / \mathrm{kg})$ to induce endometritis. The control group received normal saline. After $24 \mathrm{~h}$, mice were euthanized under $\mathrm{CO}_{2}$ asphyxiation, and the uterus tissues were harvested and stored at $-80^{\circ} \mathrm{C}$ for further studies.

\section{Histological Analysis}

Mice uterus tissues were isolated, and fixed in 10\% formalin for subsequent histological analysis. Uterus tissues were sectioned at a thickness of $5 \mu \mathrm{m}$, and then processed for hematoxylin and eosin (H\&E) staining. Finally, the sections were evaluated for histological changes with light microscopy (Olympus, Japan).

\section{Myeloperoxidase (MPO) Activity Assay}

MPO activity was measured by immunofluorescence and MPO activity assay kit according to the manufacturer's instruction (Jiancheng, China). Sections of tissue were incubated with MPO antibody (1:200) overnight at $4^{\circ} \mathrm{C}$ and then incubated with a $\mathrm{Cy} 3$ secondary antibody in the dark for $2 \mathrm{~h}$ at room temperature. Next, DAPI was used for nuclear counterstaining and observed with fluorescence microscopy (Olympus, Japan). In addition, uterine tissues were homogenized with phosphate buffered saline (PBS, PH 7.4, weight/ volume ratio 1:19). The supernatants were analyzed at an absorbance value of $460 \mathrm{~nm}$.

\section{Cell Culture and Treatment}

Bovine endometrial epithelial cell line (BEND, ATCC $®$ CRL-2398 ${ }^{\mathrm{TM}}$ ) was cultured in DMEM medium supplemented with $10 \%$ fetal bovine serum at $37{ }^{\circ} \mathrm{C}$ in a humidified atmosphere containing $5 \% \quad \mathrm{CO}_{2}$. The BEND cells were pretreated with different concentrations of fisetin (25 and $50 \mu \mathrm{g} / \mathrm{mL}$ ) for $1 \mathrm{~h}$ and then stimulated with LPS $(1 \mu \mathrm{g} / \mathrm{mL})$ for $6 \mathrm{~h}$.

\section{MTT Assay}

Cell viability was measured by 3-[4,5-dimethylthiazol2-yl]-2,5 diphenyl tetrazolium bromide (MTT) assay in accordance with the manufacturer's instructions. The BEND cells were treated with different concentrations of fisetin $(25$, and $50 \mu \mathrm{g} / \mathrm{mL})$ for $24 \mathrm{~h}$. Subsequently, MTT $(5 \mathrm{mg} / \mathrm{mL}, 150 \mu \mathrm{L}$ ) was added to the cells and incubated 
for $4 \mathrm{~h}$. The supernatant was discarded with pipette tip, and then added DMSO to dissolve the formazan crystals. The absorbance was determined at $570 \mathrm{~nm}$ using a microplate reader (Thermo, USA).

\section{Enzyme-Linked Immunosorbent (ELISA) Assay}

The uterine tissues were homogenized in pre-chilled PBS, centrifuged and collected supernatants for detecting the production of TNF- $\alpha$, and IL- $1 \beta$ using ELISA kits as the manufacturer's instructions (BioLegend, USA). In addition, BEND cells were seeded into a 6-well-plate, and the cells were treated as indicated. The cell supernatants of BEND were also collected for analysis of the TNF- $\alpha$, and IL- $1 \beta$ secretion. The optical density from each well was determined at $450 \mathrm{~nm}$ using a microplate reader (Thermo, USA).

\section{Measurement of Intracellular ROS}

The level of ROS in BEND cells was determined using the Reactive Oxygen Species Assay Kit (Beyotime, China). Cells were seeded at a density of $1 \times 10^{5}$ cells $\mathrm{mL}^{-1}$ into 6-well plates. Next, they were incubated with control media (PBS) or LPS $(1 \mu \mathrm{g} / \mathrm{mL})$ in the presence or absence of fisetin (25 and $50 \mu \mathrm{g} / \mathrm{mL}$ ) for $6 \mathrm{~h}$. The cells were incubated with 2',7'dichlorofluorescein diacetate (DCFH-DA, $10 \mathrm{mM}$ ) for $30 \mathrm{~min}$ at $37^{\circ} \mathrm{C}$ in the dark and then washed three times with PBS to remove extracellular DCFH-DA. After that, the relative levels of fluorescence were quantified by a fluorescence plate reader (485 $\mathrm{nm}$ excitation and $535 \mathrm{~nm}$ emission, Olympus).

\section{Quantitative PCR Assay}

Gene expression levels in tissues and cells were measured by qRT-PCR method. Total RNA was isolated from uterine tissues and BEND cells with TRIzol reagent (Invitrogen, USA). Next, cDNA was synthesized using a reverse transcription kit (Takara, Japan) following the manufacturer's standard protocol. The primers were displayed in Table 1. The housekeeping gene GAPDH as an internal standard. The relative fold change of gene expression was calculated by the $2^{-\Delta \Delta \mathrm{Ct}}$ comparative method.

\section{Western Blot Analysis}

The total proteins of the uterine tissues and BEND cells were collected into lysis buffer containing protease inhibitors. The lysate was centrifuged at $12,000 \mathrm{rpm}$ for $15 \mathrm{~min}$ at $4^{\circ} \mathrm{C}$, subsequently the concentration of proteins was detected using a BCA kit. Next, samples with equal amounts of protein were fractionated on $10 \%$ sodium dodecyl sulphatepolyacrylamide gel electrophoresis (SDS-PAGE) and transferred to a polyvinylidene difluoride membrane. The membrane was incubated in 5\% BSA for $2 \mathrm{~h}$ at room temperature, followed by overnight incubation at $4^{\circ} \mathrm{C}$ in specific primary antibodies. Then, the membrane was washed by Tris-buffered saline containing $0.1 \%$ Tween 20 three times and incubated in horseradish peroxidase (HRP)-labelled secondary antibody for $1 \mathrm{~h}$ at room temperature. The protein blots were visualized and analyzed by the ECLPlus Western blot Detection System (ImageQuant LAS 4000 mini, USA). $\beta$-actin as an internal standard.

Table I Primers Used for qPCR

\begin{tabular}{|l|l|l|l|}
\hline Name & \multicolumn{1}{|c|}{ Sequence $\left(\mathbf{5}^{\prime} \rightarrow \mathbf{3}^{\prime}\right):$ Forward and Reverse } & GenBank Accession No. & Product Size(bp) \\
\hline TNF- $\alpha$ & $\begin{array}{l}\text { CTTCTCATTCCTGCTTGTG } \\
\text { ACTTGGTGGTTTGCTACG }\end{array}$ & NM_013693.3 & 198 \\
\hline IL-I $\beta$ & CCTGGGCTGTCCTGATGAGAG TCCACGGGAAAGACACAGGTA & NM_00836I.4 & 131 \\
\hline COX-2 & $\begin{array}{l}\text { AATCATTCACCAGGCAAAGG } \\
\text { TAGGGCTTCAGCAGAAAACG }\end{array}$ & NM_I74445.2 & 154 \\
\hline iNOS & CCCCTGACCTTGTTCTCG CTTCTGCCCACTTCCTCC & NM_001076799.I & 229 \\
\hline Nox4 & $\begin{array}{l}\text { ACTCTGCTGGATGACTGGAAACCA } \\
\text { AGAGTAAGTCTGCAAACCAGCGGA }\end{array}$ & NM_00I304775.I & 100 \\
\hline GAPDH & CAATGTGTCCGTCGTGGATCT GTCCTCAGTGTAGCCCAAGATG & NM_00I289726.I & 124 \\
\hline
\end{tabular}



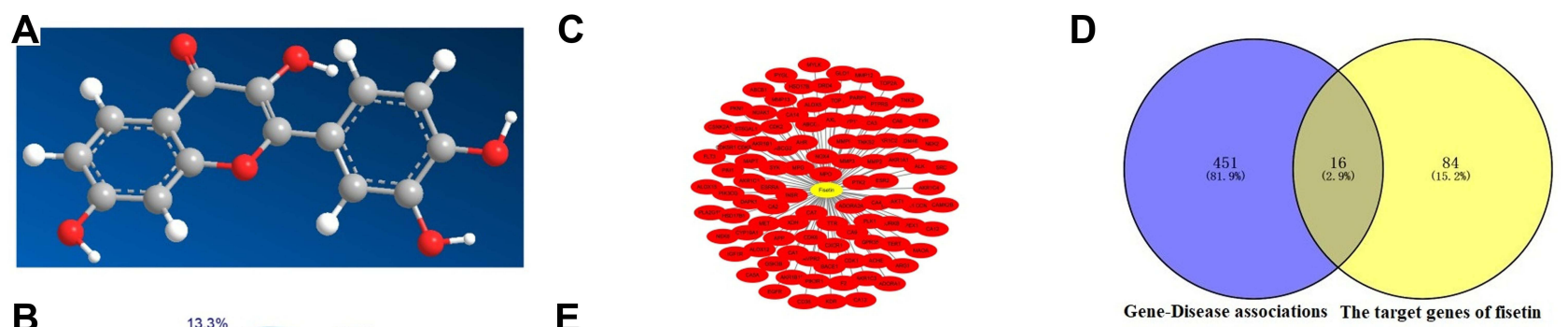

B

E
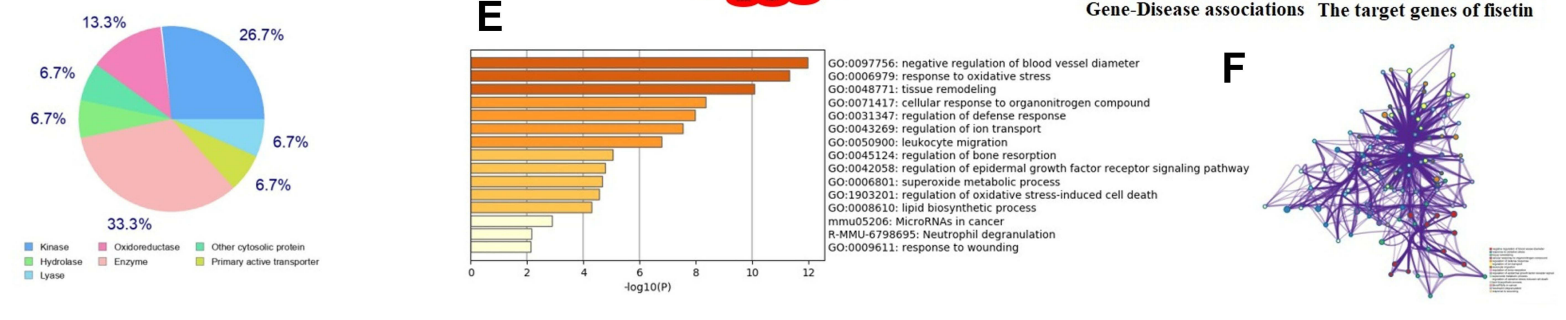

Figure 2 Network pharmacology analysis of fisetin. (A) Three dimensional structure formula of fisetin. (B) The target classes of fisetin. (C) The potential targets of fisetin were identified using the SwissTarget Prediction. (D) The common target genes of fisetin and inflammatory disease. (E and F) GO annotation and KEGG were used to analyze these target genes.

\section{Small Interfering RNA (siRNA) Transfection}

For TLR4-siRNA or Nrf2-siRNA transfection, BEND cells $\left(1 \times 10^{5}\right.$ cells $\left.\mathrm{mL}^{-1}\right)$ were grown in 6 -well plates and allowed to reach approximately $60 \%$ confluence. Transfection was performed in Opti-MEM with NCsiRNA, TLR4-siRNA or Nrf2-siRNA using Lipofectamine $^{\mathrm{TM}} 2000$ (Invitrogen, USA) according to the manufacturer's protocol. After $24 \mathrm{~h}$, the treatment group was pre-treated with fisetin $(50 \mu \mathrm{g} / \mathrm{mL})$ for $1 \mathrm{~h}$, and then LPS $(1 \mu \mathrm{g} / \mathrm{mL})$ was added for $6 \mathrm{~h}$. Finally, the cells were cleaved for further analysis.

\section{Immunofluorescence Staining}

BEND cells were grown in twelve-well-plate. After the cells were treated as indicated, immunofluorescence staining was performed. Sections of BEND cell were incubated with p-p65 or TLR4 antibody overnight at $4{ }^{\circ} \mathrm{C}$ and then incubated with a $\mathrm{Cy} 3$ secondary antibody in the dark for $2 \mathrm{~h}$ at room temperature. Next, p-p65 or TLR4 protein was mounted using a mounting medium supplemented with DAPI for nuclear counterstaining and observed using fluorescence microscopy (Olympus, Japan).

\section{Data and Statistical Analysis}

Data are presented as mean \pm SEM. All data were analysed using GraphPad Prism 5 (GraphPad InStat
Software, San Diego, USA). Comparison between groups was made with the one-way ANOVA followed by Dunnett's test. For all one-way ANOVAs, post tests were run only if $F$ achieved $P<0.05$ and there was no significant variance inhomogeneity. Statistical significance was set to $P<0.05$.

\section{Materials and Reagents}

Fisetin (purity $\geq 98 \%$ ) was obtained from Shanghai Yuanye Bio-Technology Co., Ltd. (Shanghai, China). The purity of fisetin was detected by High Performance Liquid Chromatography (HPLC). This test was processed on EChrom2000 DAD Data System (Elite, China). Chromatography was performed by Hyper ODS2 C18 column. Elution was processed with acetonitrile $/ 0.2 \%$ phosphoric acid water (45:55). The flow rate was $1.0 \mathrm{~mL} / \mathrm{min}$, which was determined at $355 \mathrm{~nm}$ (as shown in Figure 1B). LPS (E. coli 055: B5) was purchased from Sigma (St. Louis, USA). The antibodies were obtained from Cell Signaling Technology (Beverly, USA).

\section{Results}

\section{Network Pharmacology Analysis of Fisetin}

As displayed in Figure 2, our findings showed that fisetin has good druggability with 16 putative identified target genes. GO annotation and KEGG analysis 


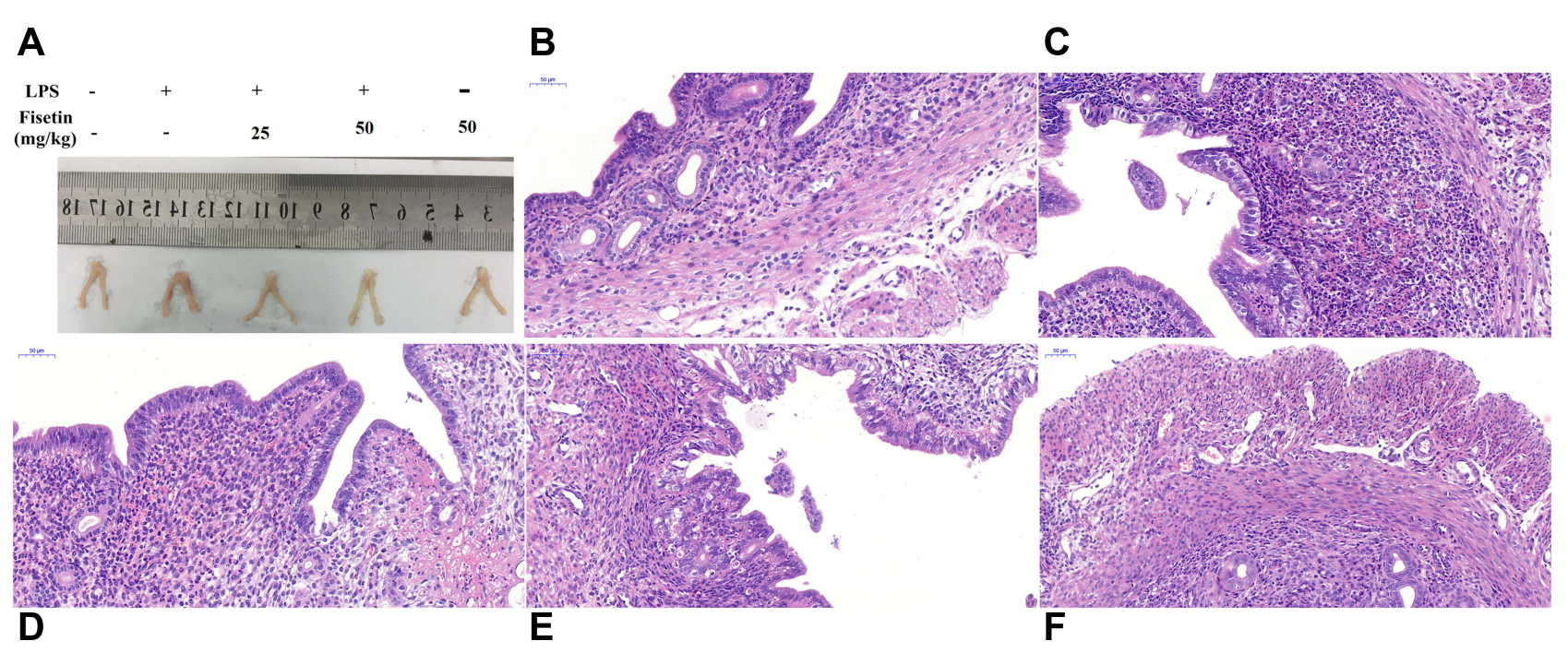

Figure 3 Effects of fisetin on LPS-induced uterine injury. (A) Morphology of the uterus. (B) Control group. (C) LPS group. (D and E) LPS + fisetin (25, 50 mg/kg) treatment groups. (F) Fisetin group (50 mg/kg).

revealed that these target genes were associated with oxidative stress.

\section{Fisetin Alleviates LPS-Induced Uterine Injury}

The histological changes of LPS-induced endometritis were evaluated by H\&E staining, as shown in Figure 3. Uterus morphology was observed after LPS or fisetin administration (Figure 3A). Compared with the control group or fisetin-treated alone group (Figure 3B and F), LPS induced evidently pathologic changes, with extensive inflammatory cell infiltration and the structure of the uterus was damaged (Figure 3C). However, LPSinduced severe histopathological changes were significantly weakened by treatment of fisetin (Figure 3D and E).

\section{Fisetin Decreased LPS-Induced Inflammatory Responses}

MPO is a peroxidase enzyme used to quantify the neutrophil infiltration in inflammatory diseases. ${ }^{22}$ As shown in Figure 4A and B, compared with the control group or fisetin-treated alone group, the MPO activity was greatly increased in LPS group. However, the MPO activity was dose-dependently reduced by fisetin treatment (25, and $50 \mathrm{mg} / \mathrm{kg}$ ). Moreover, to analyze the effects of fisetin on LPS-induced inflammatory response, the expression of TNF- $\alpha$, and IL- $1 \beta$ in uterine tissues were measured by qRT-PCR method. The results showed that the expressions of TNF- $\alpha$ and IL$1 \beta$ were greatly increased in LPS treatment group, whereas treatment with fisetin dose-dependently decreased the level of these cytokines (Figure 4C).

\section{Fisetin Inhibited TLR4 Expression and NF- $\kappa B$ Pathway in LPS-Induced Endometritis}

TLR4 is an important sensor for LPS, which activates the signaling cascades and promotes inflammation. ${ }^{23}$ Thus, we determined whether fisetin could relieve the inflammatory response by inhibiting TLR4 expression, Western blot method was performed. The result indicated that the expression of TLR4 was inhibited by fisetin administration (Figure 5A). Besides, NF- $\kappa \mathrm{B}$ pathway plays critical role in mediating inflammatory cytokines secretion, ${ }^{24}$ we also detected the effects of fisetin on LPS-activated NF- $\kappa B$ pathway. As shown in Figure 5B, fisetin significantly suppressed the phosphorylation of $\mathrm{p} 65$ and $\mathrm{I} \kappa \mathrm{B} \alpha$ proteins.

\section{Fisetin Exposure Blocked LPS-Induced Inflammatory Responses in BEND Cells}

The effect of different concentrations of fisetin on cell viability was assessed by MTT assay. The result 
A

DAPI

MPO

Merge

Control

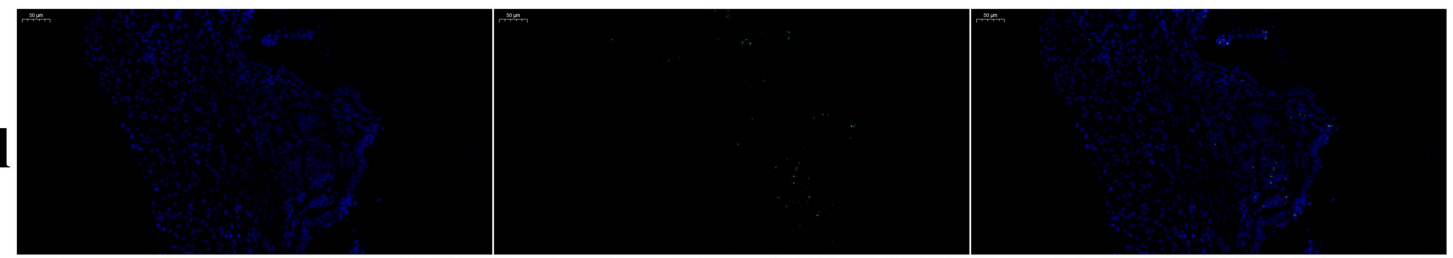

LPS

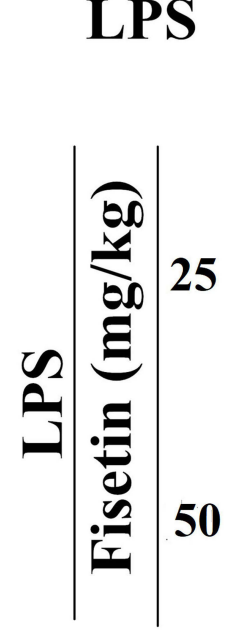

Fisetin $50 \mathrm{mg} / \mathrm{kg}$

B

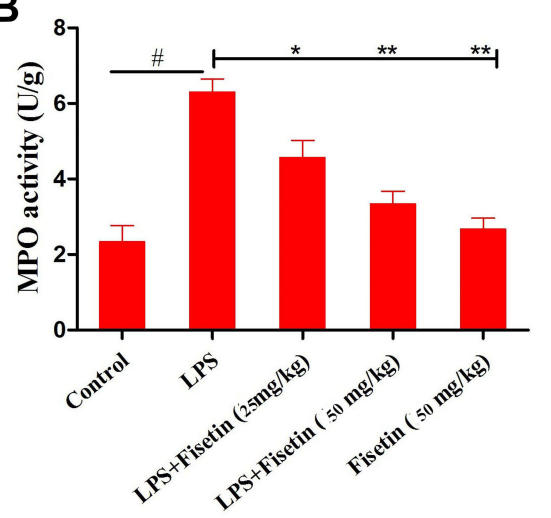

C

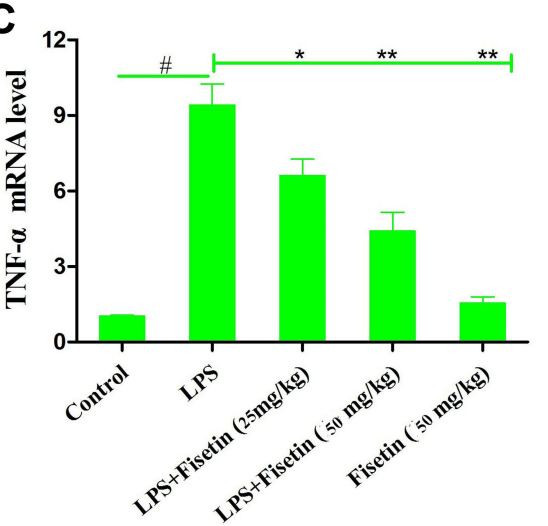

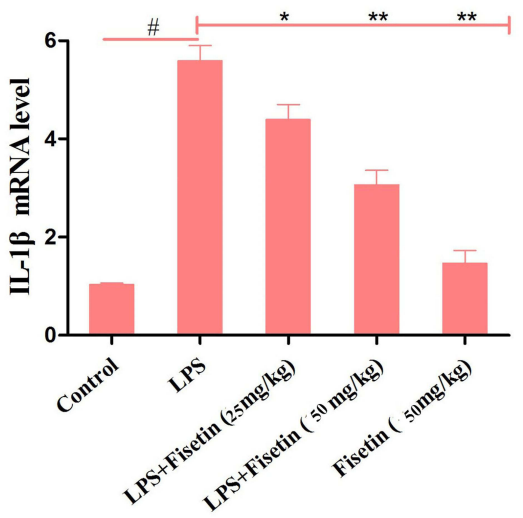

Figure 4 Effects of fisetin on LPS-induced inflammatory responses in mice. (A and B) MPO activity. (C) Expression of TNF- $\alpha$ and IL-I $\beta$ mRNA in tissues. GAPDH serves as the control. All data are represented as the mean \pm S.E.M. of three independent experiments. Hash marks indicate $P<0.05$ versus control group. Asterisks indicate $P<0.05$ versus LPS group. Double asterisk indicate $P<0.01$ compared with LPS group.

indicated that cell viability was not affected by fisetin treatment (Figure 6A). Thus, the concentrations of fisetin $(25,50 \mu \mathrm{g} / \mathrm{mL})$ was chosen for exposure to
BEND cells for $1 \mathrm{~h}$, subsequently challenged with LPS. The production of TNF- $\alpha$ and IL- $1 \beta$ in BEND cells was determined using ELISA kit. The result 

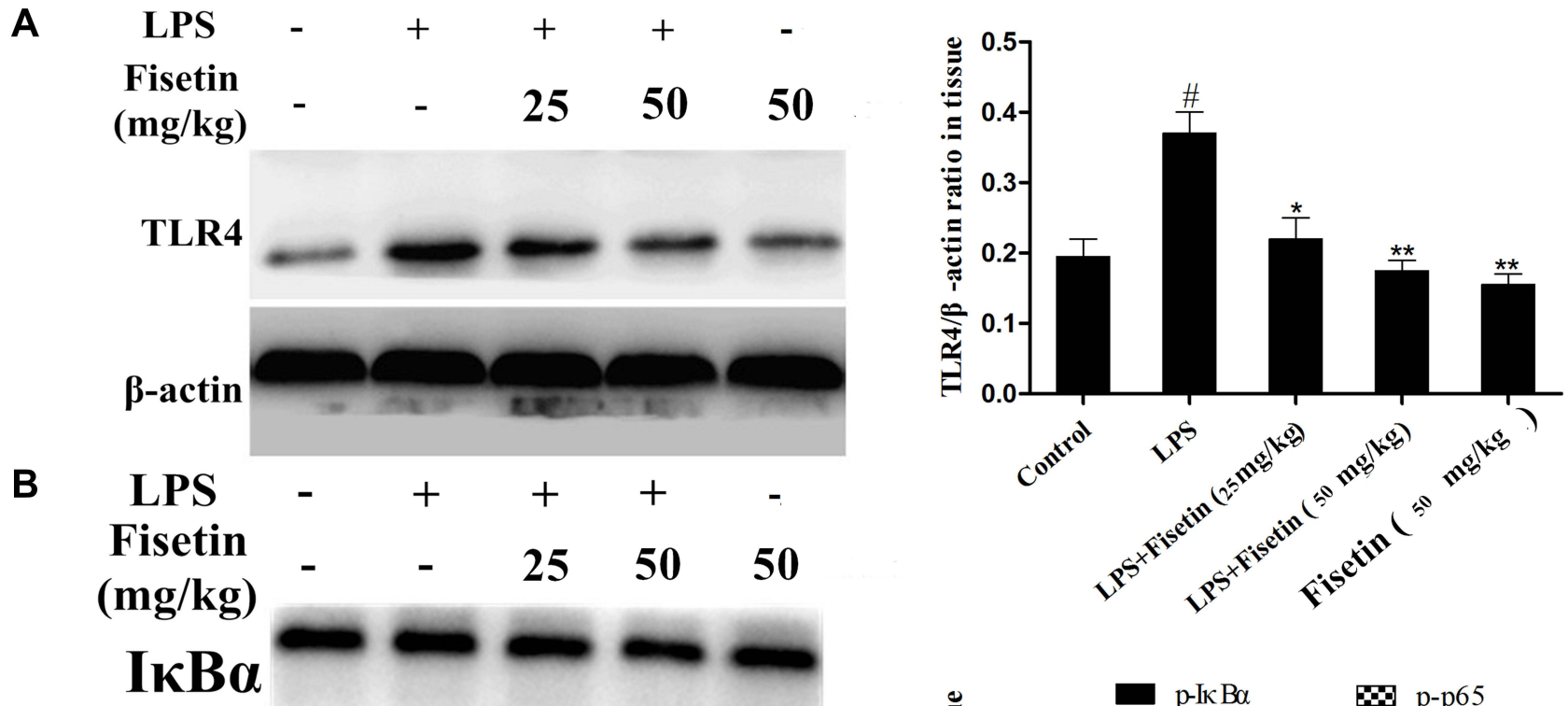

\section{p-ІкB $\alpha$}
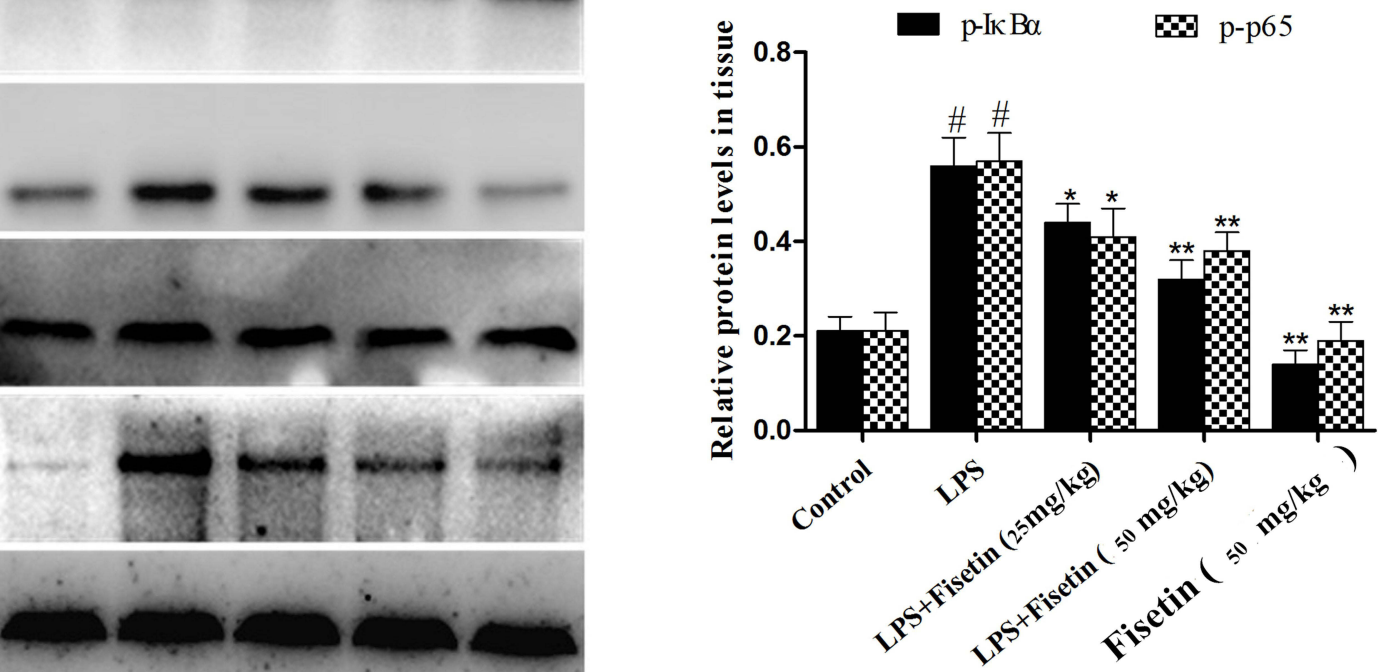

Figure 5 Effects of fisetin on TLR4 expression and NF-KB pathway activation in LPS-induced endometritis. (A) Protein expression of TLR4 in uterine tissues. (B) Proteins expression of $\mathrm{I} \mathrm{KB} \alpha$ and $\mathrm{p} 65$ in uterine tissues. $\beta$-actin served as an internal control. All data are represented as the mean \pm S.E.M. of three independent experiments. Hash marks indicate $P<0.05$ versus control group. Asterisks indicate $P<0.05$ versus LPS group. Double asterisk indicate $P<0.01$ compared with LPS group.

indicated that the secretion of TNF- $\alpha$ and IL-1 $\beta$ was significantly increased in the LPS group, whereas fisetin dose-dependently reduced the production of TNF- $\alpha$ and IL-1 $\beta$ (Figure 6B). Moreover, iNOS and COX-2 are also key cytokines in oxidative stress. The levels of iNOS and COX-2 in BEND cells were detected by qRT-PCR method. As shown in Figure 6C, LPS administration markedly increased iNOS and COX-2, whereas the expression of iNOS and COX-2 were reduced by pretreatment with fisetin in a dose dependent way.

\section{Fisetin Treatment Alleviated LPS-Induced}

\section{Oxidative Stress}

Since oxidative damage plays a pivotal role in LPSinduced inflammatory process, and ROS often serve as signaling molecules involved in the inflammatory regulation. ${ }^{13}$ Therefore, we detected whether fisetin 

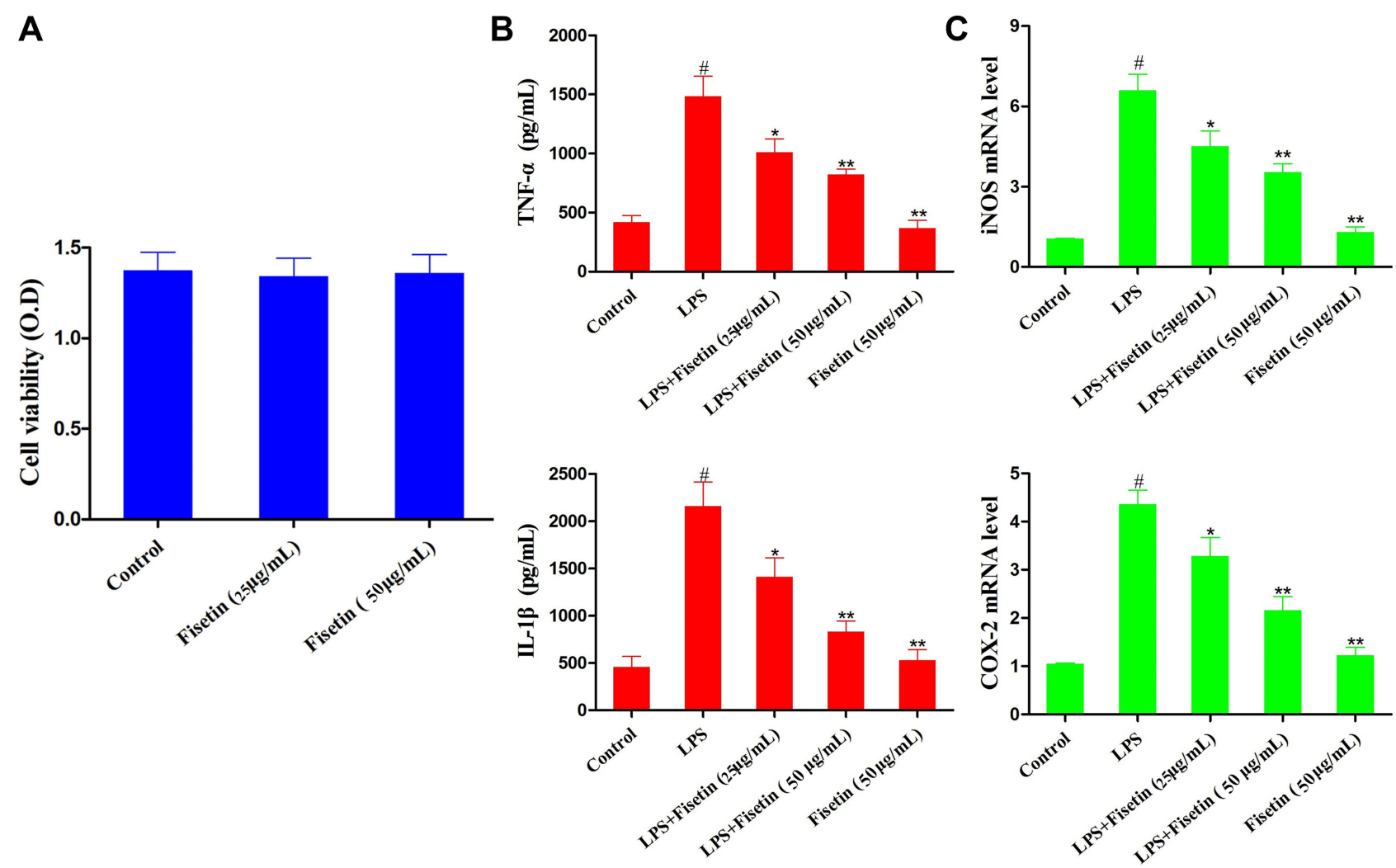

Figure 6 Effects of fisetin on LPS-induced inflammatory responses in BEND cells. Cells were subjected to different concentrations of fisetin for I h, and then challenged with LPS $(I \mu \mathrm{g} / \mathrm{mL})$. (A) Effect of fisetin on the cell viability was measured by MTT assay. (B) Effects of fisetin on the expression of TNF- $\alpha$ and IL-I $\beta$ were determined by ELISA assay. (C) Expression of iNOS and COX-2 mRNA in LPS-stimulated BEND cells using qRT-PCR method. GAPDH served as the control. All data are represented as the mean \pm S.E.M. of three independent experiments. Hash marks indicate $P<0.05$ versus control group. Asterisks indicate $P<0.05$ versus LPS group. Double asterisk indicate $P<0.01$ compared with LPS group.

pretreatment could inhibit LPS-triggered oxidative stress. As shown in Figure 7A, the results showed that fisetin dose-dependently inhibited LPS-induced ROS production in BEND cells. Additionally, the Nrf2/HO-1 pathway was found to be associated with antioxidant stress and scavenging of ROS. ${ }^{25}$ Western blot analysis indicated that the expression of $\mathrm{Nrf} 2$ and HO-1 proteins were increased by the fisetin treatment (Figure 7B).

\section{Fisetin Suppressed TLR4 Expression and NF-kB Pathway Activation in BEND Cells} The expression of TLR4 in LPS-stimulated BEND cells was determined by Western blot method. The result suggested that TLR4 protein was significantly increased in LPS group, which was dose-dependently down-regulated by fisetin administration (Figure 8A). The NF- $\mathrm{KB}$ signaling pathway was also determined by
Western blot assay. We found that the phosphorylation of p65 and $\mathrm{I} \kappa \mathrm{B} \alpha$ proteins were increased after LPS challenge, whereas the phosphorylation of p65 and $\mathrm{I} \kappa \mathrm{B} \alpha$ proteins were decreased by fisetin treatment (Figure 8B).

\section{Effects of TLR4-siRNA Transfection on LPS-Induced Inflammatory Response}

In order to further confirm the anti-inflammatory mechanism of fisetin is through TLR4-mediated pathway, specific interference RNA (TLR4-siRNA) transfection was performed in BEND cells. The cells were subjected to transfection with either control siRNA or TLR4 siRNA. Immunofluorescence assay displayed that excessive expression of TLR4 in LPS group that was decreased by TLR4-siRNA treatment (Figure 9A). Subsequently, immunofluorescence assay was also 


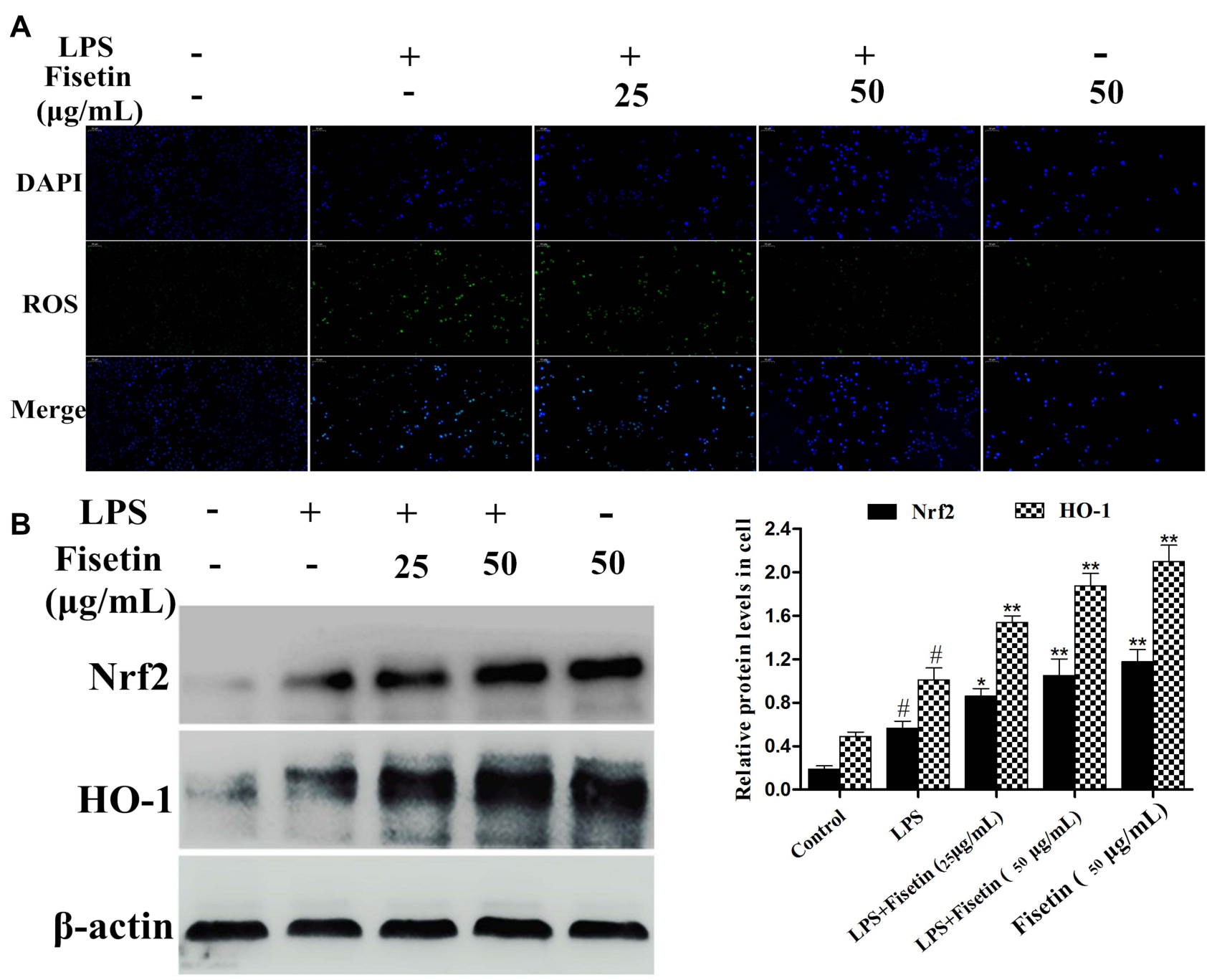

Figure 7 Effects of fisetin on LPS-induced oxidative stress. (A) Effect of fisetin on LPS-triggered ROS production in BEND cells. (B) Effect of fisetin on Nrf2 and HO-I protein expression levels in LPS-triggered BEND cells. $\beta$-actin served as internal control. All data are represented as the mean \pm S.E.M. of three independent experiments. Hash marks indicate $P<0.05$ versus control group. Asterisks indicate $P<0.05$ versus LPS group. Double asterisk indicate $P<0.01$ compared with LPS group.

performed to determine the translocation of $\mathrm{NF}-\kappa \mathrm{B}$ p65, the result indicated that the expression of p65 was significantly decreased in the nucleus with the treatment of TLR4-siRNA and fisetin (Figure 9B). The expression of Nox4 was reduced in TLR4-siRNA administration (Figure 9C). ROS often participate in the regulation of inflammatory process, thus, we also determined the effect of TLR4-siRNA transfection on ROS production. As shown in Figure 9D, LPS-induced ROS excessive production that was decreased by TLR4-siRNA administration in BEND cells. The above results indicate that fisetin inhibits the inflammatory response through TLR4-mediated ROS/NF- $\mathrm{BB}$ signaling pathway.

\section{Effects of Nrf2-siRNA Transfection on} Fisetin-Induced HO-I Protein Expression

To further examine the role of Nrf2 in fisetin-induced HO1 protein expression, the specific siRNA was used to silence Nrf2 expression in BEND cells. After the cells were treated as indicated, Western blot assay was performed. As shown in Figure 10A, compared with negative control, the Nrf2 siRNA treatment reduced the expression of Nrf2 protein. Additionally, we then investigated whether Nrf2 siRNA transfection inhibited fisetininduced HO-1 protein expression. The result suggested that fisetin enhanced the HO-1 protein expression that was significantly decreased by Nrf2 siRNA administration compared to the negative control (Figure 10B). 

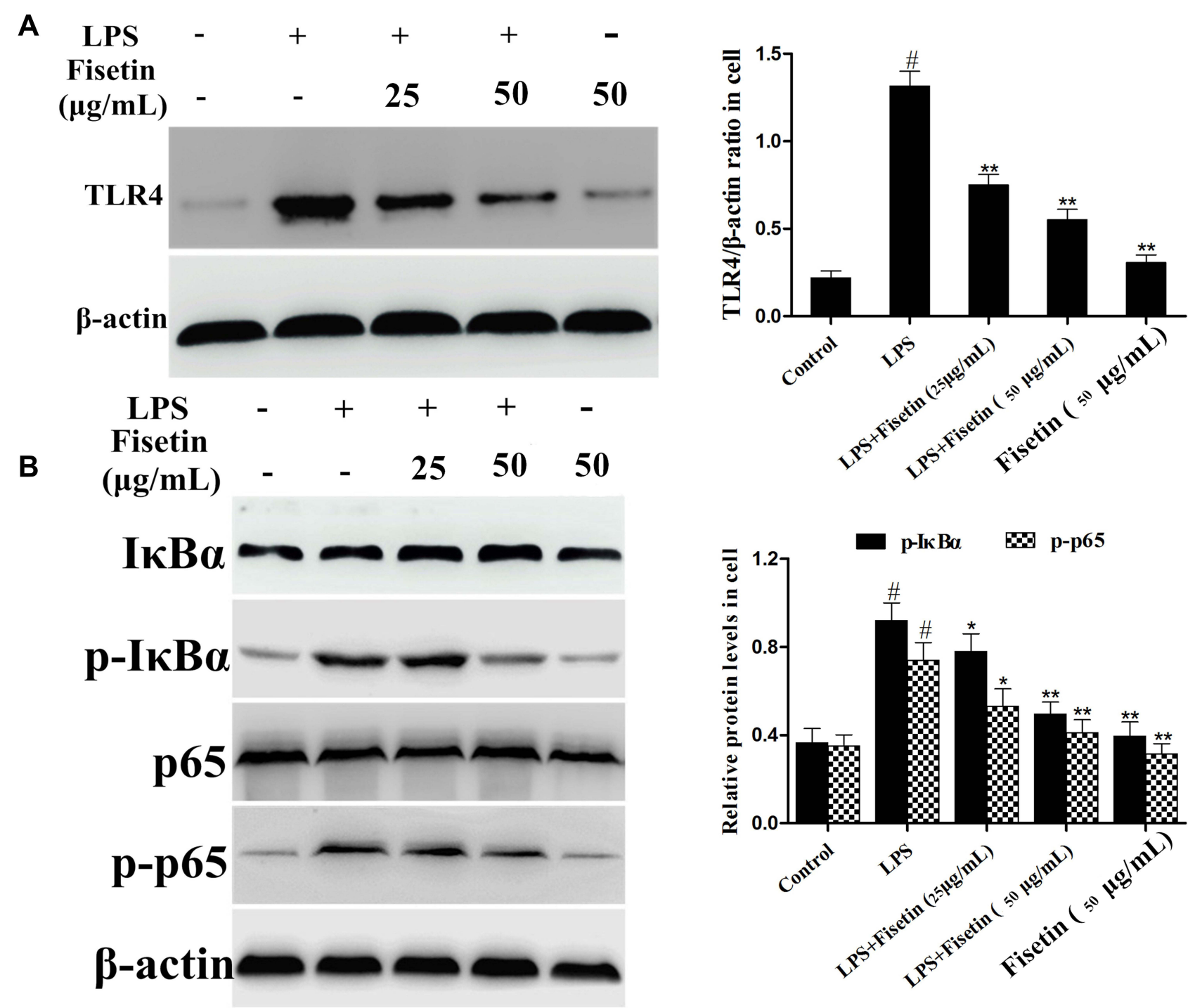

Figure 8 Effects of fisetin on TLR4 expression and NF- $\kappa B$ pathway activation in BEND cells. (A) Expression of TLR4 was detected by Western blot method in LPSstimulated BEND cells. (B) Proteins expression of $1 \kappa B \alpha$ and $p 65$ in LPS-stimulated BEND cells. $\beta$-actin served as internal control. All data are represented as the mean \pm S.E. M. of three independent experiments. Hash marks indicate $P<0.05$ versus control group. Asterisks indicate $P<0.05$ versus LPS group. Double asterisk indicate $P<0.01$ compared with LPS group.

\section{Effects of Nrf2-siRNA Transfection on LPS-Induced Inflammatory Response}

There is growing evidence indicated that Nrf2/HO-1 pathway played vital role in inhibiting oxidative stress and inflammatory responses. We therefore utilized Nrf2 siRNA transfection to determine whether the anti-oxidant and anti-inflammatory activities of fisetin were connected with HO-1 expression. BEND cells were pretreated with fisetin $(50 \mu \mathrm{g} / \mathrm{mL})$ for $1 \mathrm{~h}$ with Nrf2 siRNA or control siRNA, and then challenged by LPS. As shown in Figure 11, silencing Nrf2 abrogated the inhibitory effects of fisetin on LPS-induced inflammatory mediators TNF- $\alpha$, IL-1 $\beta$ secretion, Nox 4 and ROS production.

\section{Discussion}

Oxidative stress is a condition in which generation of ROS beyond the capacity of the antioxidant defense system. ${ }^{26}$ ROS, belonging to oxidative mediated molecules, are reactive molecules and free radicals derived from molecular oxygen. ${ }^{27}$ An increasing body of evidence demonstrated that ROS play important role in the invasion of microbial pathogens, such as LPS infection. ${ }^{28}$ Dietary polyphenols, 
A

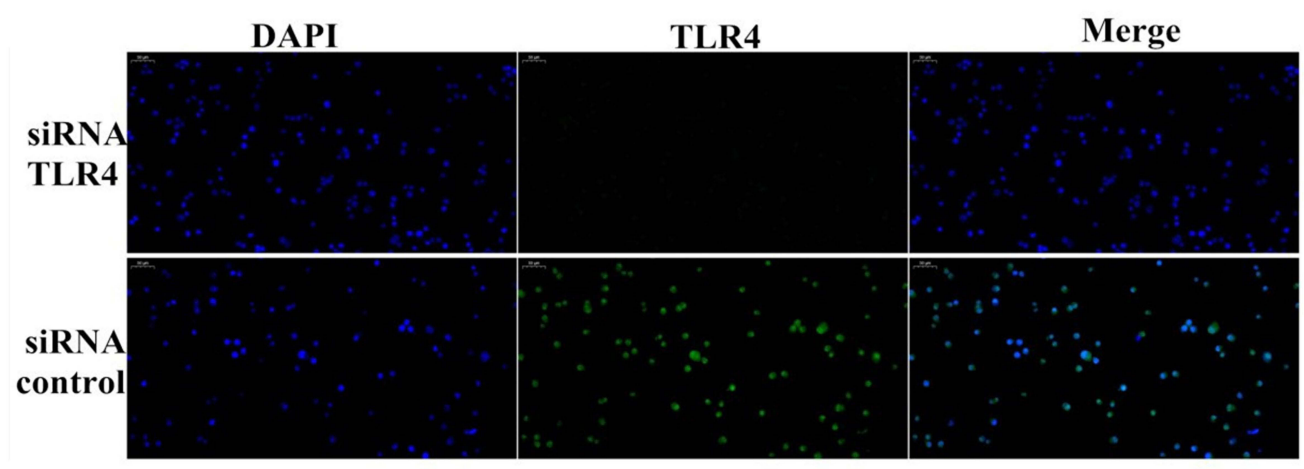

B

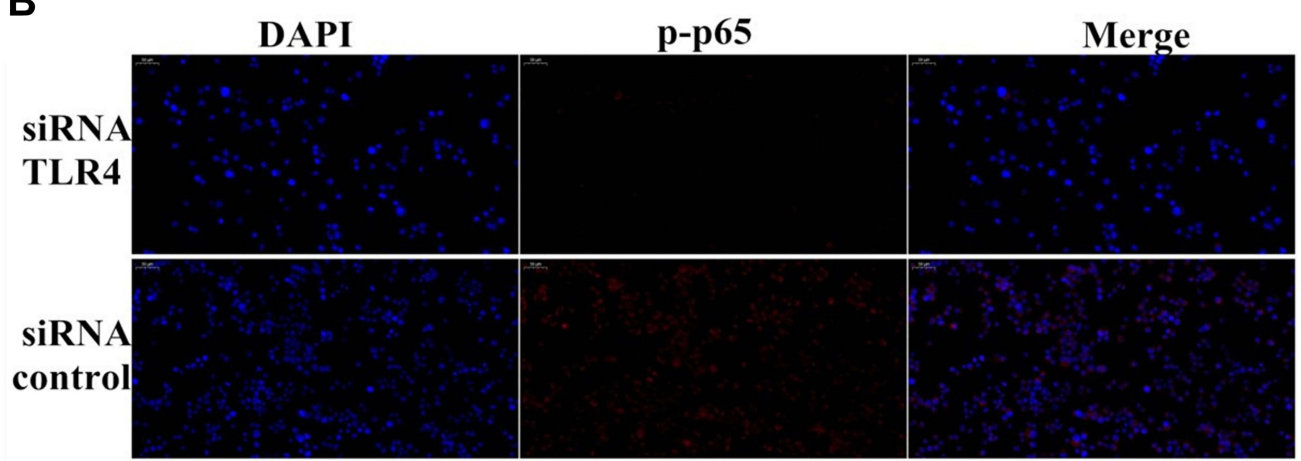

C
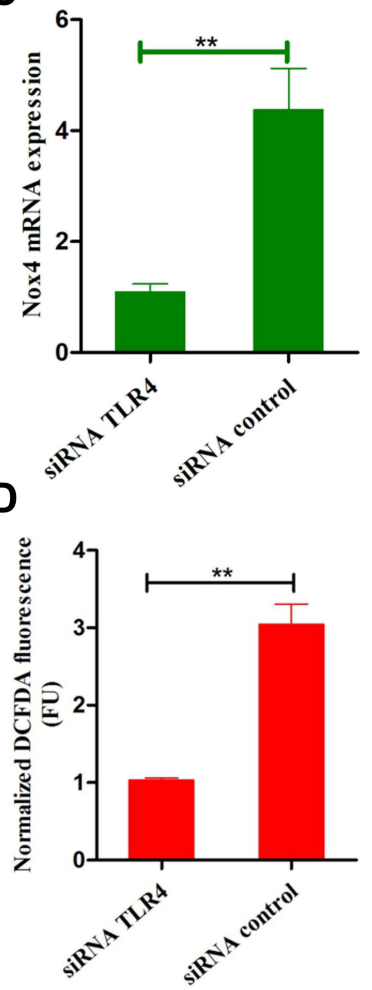

Figure 9 Effects of TLR4-siRNA transfection on LPS-induced inflammatory response. Cells were subjected to transfection with either control siRNA or TLR4 siRNA. (A) The interfering efficiency of TLR4 siRNA was measured by immunofluorescence technique. (B) Immunofluorescence assay was performed to determine the translocation of NF- $\mathrm{KB}$ p65 after silencing TLR4 in LPS-stimulated BEND cells. (C) The expression of Nox4 in TLR4-siRNA transfected cells. (D) The effect of TLR4-siRNA transfection on ROS production in LPS-stimulated BEND cells. All data are represented as the mean \pm S.E.M. of three independent experiments. Double asterisk indicate $P<0.0$ I compared with LPS group.

such as fisetin, have been extensively studied for their efficient anti-inflammatory, and antioxidant activities. ${ }^{29,30}$ In the present study, we aimed to investigating whether fisetin could inhibit LPS-induced endometritis mouse model in vivo, and its antioxidant and anti-inflammatory mechanism was uncovered in LPS-stimulated BEND cells in vitro.

Accumulating evidences indicate that LPS contributes to varying degrees of damage to the organism, including lung and uterus injuries. ${ }^{21,23}$ In vivo experiments showed that fisetin mitigated inflammatory damage and reduced MPO activity in LPS-stimulated mouse endometritis. These results suggested that fisetin had a protective function on LPS-induced endometritis.

Long-term inflammatory mediators, including TNF$\alpha$, IL-1 $\beta$, iNOS, Nox4, and COX-2, are closely associated with the development of acute and chronic inflammation diseases. ${ }^{13}$ Previous studies have demonstrated that LPS can promote the secretion of proinflammatory cytokines, such as TNF- $\alpha$, IL- $1 \beta .{ }^{21}$ TNF- $\alpha$ is a potent activator for activation of NADPH oxidase, resulting in the formation of ROS. ${ }^{31} \mathrm{IL}-1 \beta$ is secreted by macrophages upon stimulation with LPS or other inflammatory stimuli. ${ }^{32}$ Besides, iNOS, and COX-2 have been reported to play important roles in the development of inflammatory diseases. ${ }^{33,34}$ Our findings indicated that fisetin administration effectively decreased TNF- $\alpha$, and IL- $1 \beta$ secretion as well as inhibited iNOS, and COX-2 expression in LPS-induced endometritis and BEND cells. TLRs are vital constituent of the innate immune response, which activates a variety of pathways that rely on rapid identification of pathogenic microbial components. ${ }^{35}$ TLR4 was demonstrated as the important receptor for ROS 


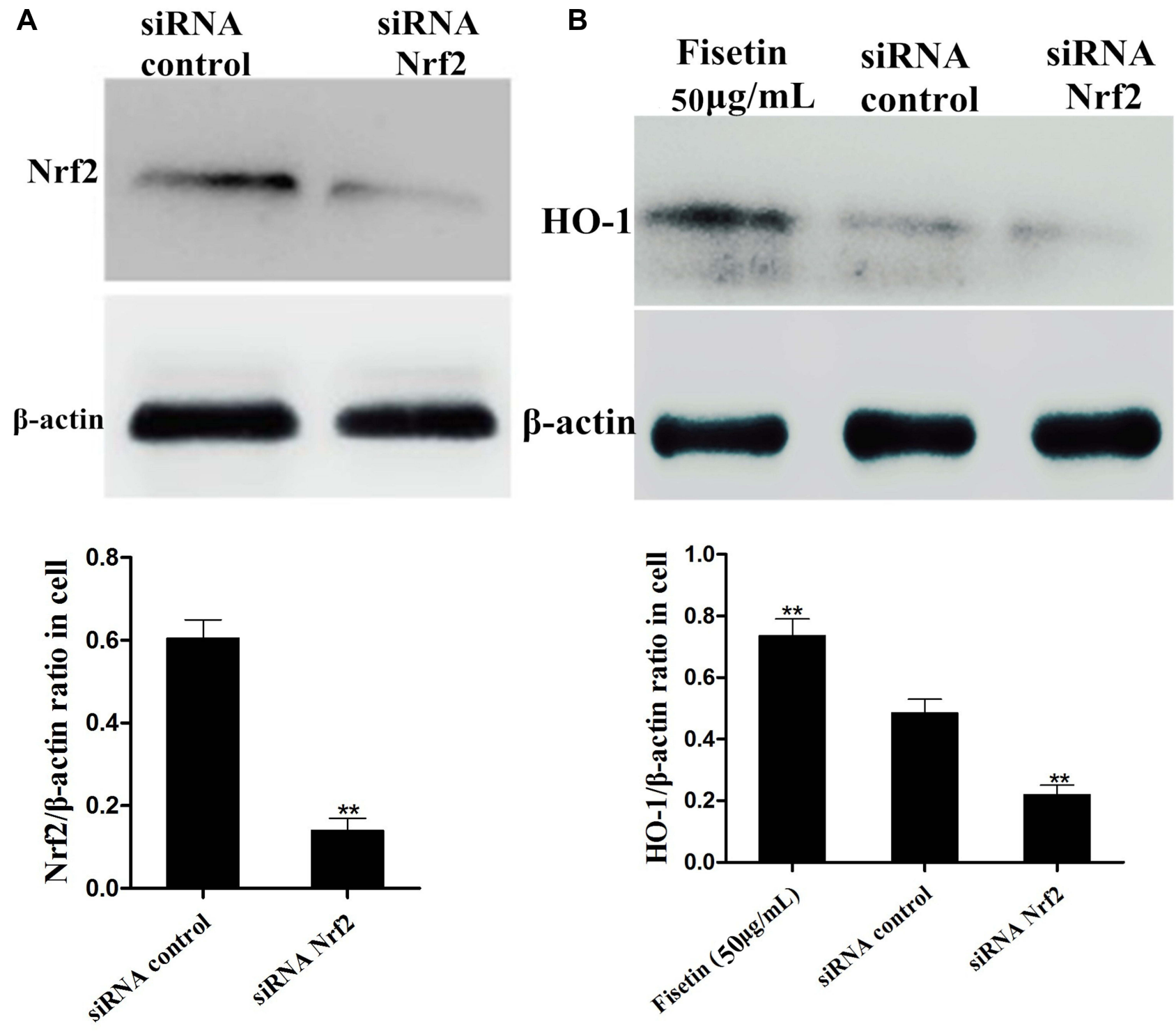

Figure 10 Effects of Nrf2-siRNA transfection on fisetin-induced HO-I protein expression. The specific siRNA was used to silence Nrf2 expression in BEND cells. (A) The interfering efficiency of Nrf2 siRNA was determined by Western blot. (B) The effect of Nrf2 siRNA transfection on fisetin-induced HO-I protein expression was also measured by Western blot. $\beta$-actin served as control. All data are represented as the mean \pm S.E.M. of three independent experiments. Double asterisk indicate $P<0.0 \mathrm{I}$ compared with LPS group.

production in LPS stimulation. ${ }^{12}$ In addition, NF- $\mathrm{KB}$ is a transcription factor that induces the inflammatory genes expression. ${ }^{36}$ Recently, it has been shown that the NF- $\mathrm{kB}$ pathway is mediated by ROS. ${ }^{37}$ Therefore, we attempted to explore whether the anti-inflammatory mechanism of fisetin suppressed the activation of NFKB through TLR4-mediated ROS pathway. In our experiments, LPS increased TLR4 expression, which was dramatically decreased by fisetin administration. Silencing TLR4, the production of ROS and NF- $\mathrm{KB}$ pathway activation were both decreased by TLR4siRNA or fisetin $(50 \mu \mathrm{g} / \mathrm{mL})$ in LPS-induced BEND cells. Taken together, these investigations implied that fisetin inhibited the activation of NF- $\kappa \mathrm{B}$ via TLR4mediated ROS signaling pathway.

Moreover, the Nrf2/HO-1 pathway has a vital role in inhibiting oxidative stress and inflammatory response. ${ }^{38}$ In this study, fisetin treatment could effectively up-regulated $\mathrm{Nrf} 2$ and HO-1 expression. Silencing Nrf2, the expression of HO-1 was suppressed and abrogated the inhibitory 
A

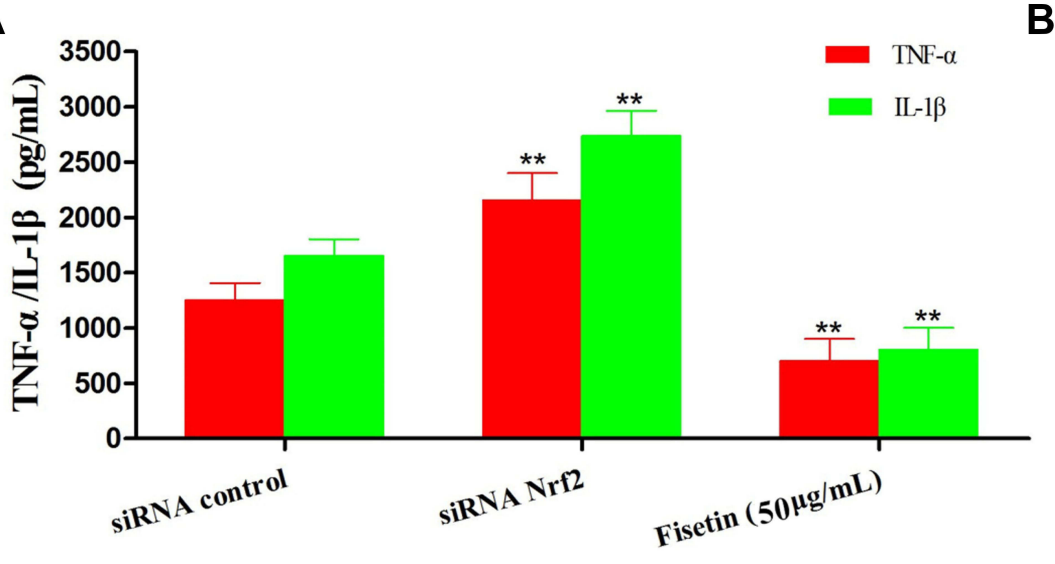

B

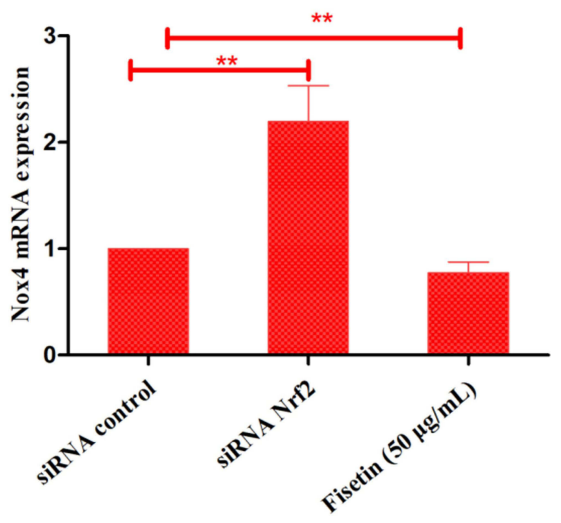

C

LPS $(1 \mu \mathrm{g} / \mathrm{mL})$

\section{siRNA control}

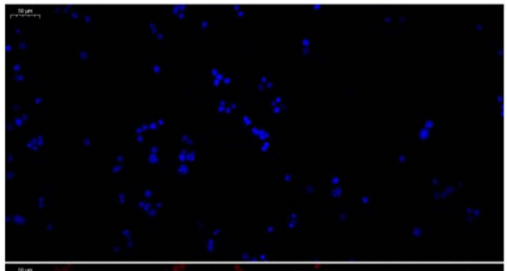

DAPI

ROS

Merge

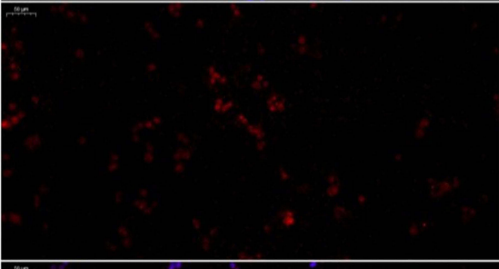

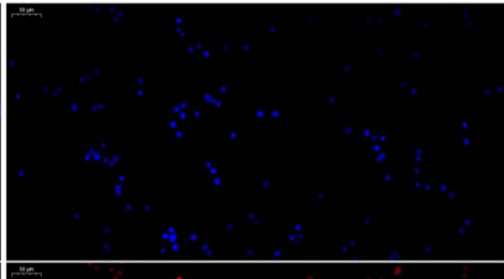

Fisetin $(50 \mu \mathrm{g} / \mathrm{mL})$
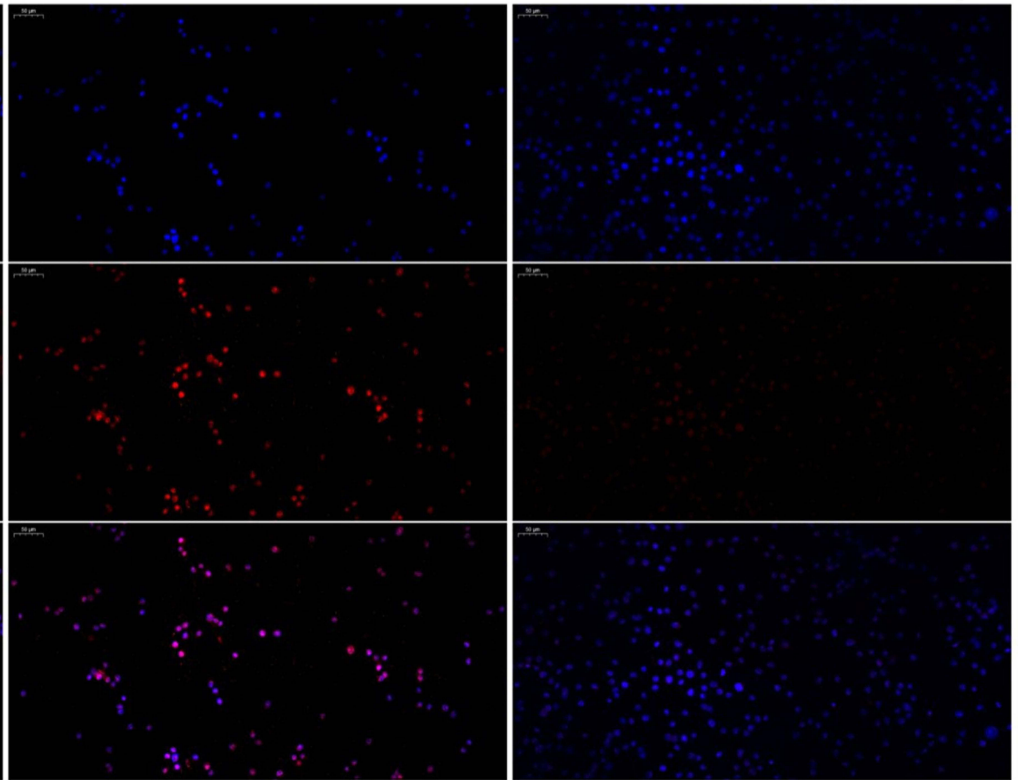

Figure II Effects of Nrf2-siRNA transfection on LPS-induced inflammatory response. BEND cells were treated as indicated. After silencing Nrf2, the inhibitory effects of fisetin on LPS-induced inflammatory mediators TNF- $\alpha$, IL-I $\beta$ secretion, Nox4 and ROS production were further analysis. (A) The expressions of TNF- $\alpha$, IL-I $\beta$ were determined by ELISA kit. (B) The expression of Nox4 in Nrf2-siRNA transfected cells. (C). The production of ROS was detected by immunofluorescence technique. All data are represented as the mean \pm S.E.M. of three independent experiments. Double asterisk indicate $P<0.01$ compared with LPS group.

effects of fisetin on LPS-induced inflammatory mediators secretion, and ROS production. These results suggested that the fisetin exhibited protection effect on LPSinduced inflammation via up-regulating the Nrf2/HO-1 pathway.

Collectively, as illustrated in Figure 12, our results firstly indicated that fisetin effectively protected against LPSinduced oxidative stress and inflammation in vitro and in vivo. These beneficial effects may be the result of inhibition of ROS production, reduced the TNF- $\alpha$ and IL- $1 \beta$ secretion, and decreased iNOS, COX-2, and Nox4 expression. The underlying mechanisms of these findings may be closely correlated to inhibition of TLR4-mediated ROS/NF$\kappa \mathrm{B}$ and activation of the $\mathrm{Nrf} / \mathrm{HO}-1$ pathways.

\section{Acknowledgments}

This research was funded by the Key Laboratory of Fujian Universities Preventive Veterinary Medicine and Biotechnology, Longyan University, Longyan 364012, China (No.2020KF02), and Longyan University \& Fujian 


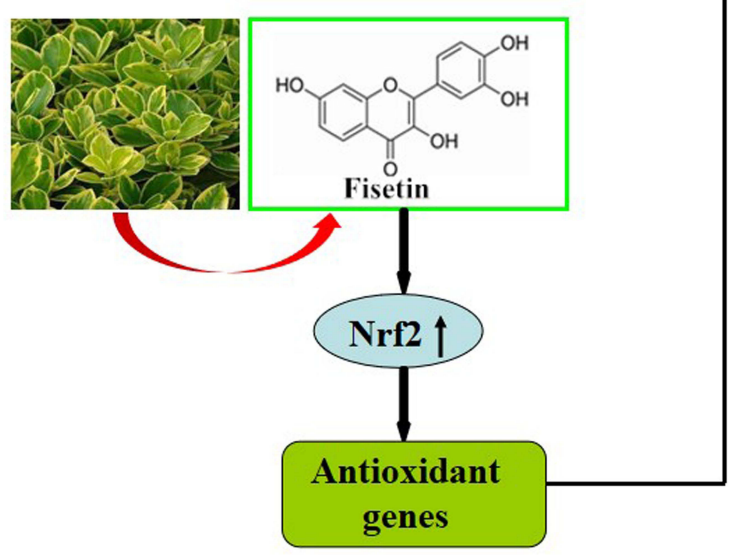

\section{$\perp$ Inhibited $\uparrow$ Activated}

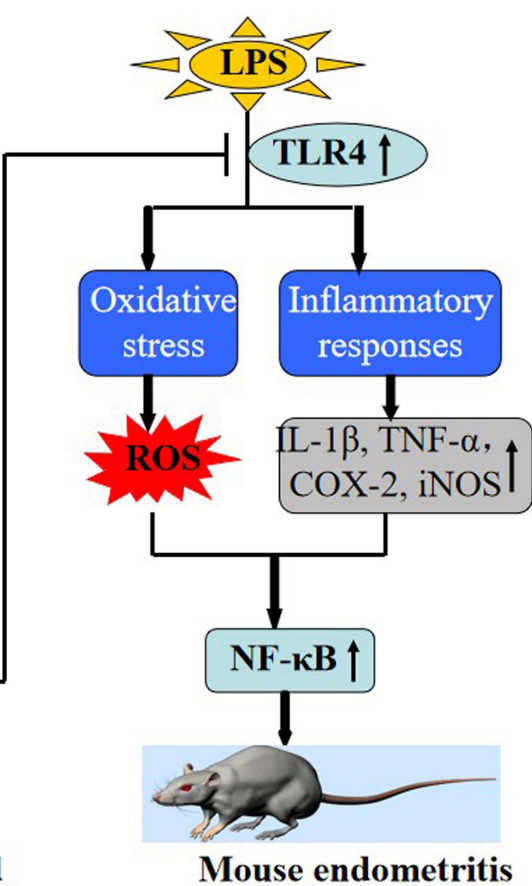

Figure 12 Scheme summarizing the protective effects of fisetin on LPS-induced inflammatory response. Fisetin effectively protected against LPS-induced oxidative stress and inflammation which may be closely correlated to inhibition of TLR4-mediated ROS/NF- $\mathrm{KB}$ and activation of the Nrf2/HO-I pathways.

Provincial Key Laboratory for Prevention and Control of Animal Infectious Diseases and Biotechnology, Longyan 364012, China (No.ZDSYS2020001); and supported by "the Fundamental Research Funds for the Central Universities (No.2021QNA6023)".

\section{Disclosure}

The authors declare no conflicts of interest in this work.

\section{References}

1. Kasimanickam RK, Kasimanickam VR, Olsen JR, Jeffress EJ, Moore DA, Kastelic JP. Associations among serum pro- and anti-inflammatory cytokines, metabolic mediators, body condition, and uterine disease in postpartum dairy cows. Reprod Biol Endocrinol. 2013;11:103. doi:10.1186/1477-7827-11-103

2. Swangchan-Uthai T, Lavender CR, Cheng Z, Fouladi-Nashta AA, Wathes DC. Time course of defense mechanisms in bovine endometrium in response to lipopolysaccharide. Biol Reprod. 2012;87(6):135. doi:10.1095/biolreprod.112.102376

3. Piras C, Guo Y, Soggiu A, et al. Changes in protein expression profiles in bovine endometrial epithelial cells exposed to E. coli LPS challenge. Mol. BioSyst. 2017;12(2):392-405. doi:10.1039/ C6MB00723F

4. Prince PD, Fischerman L, Toblli JE, Fraga CG, Galleano M. LPSinduced renal inflammation is prevented by (-)-epicatechin in rats. Redox Biol. 2017;11:342-349. doi:10.1016/j.redox.2016.12.023

5. Cao W, Zhang W, Liu J, et al. Paeoniflorin improves survival in LPS-challenged mice through the suppression of TNF-alpha and IL-1beta release and augmentation of IL-10 production. Int Immunopharmacol. 2011;11(2):172-178. doi:10.1016/j.intimp.2010.11.012
6. Han J, Liu L, Yu N, et al. Polysaccharides from Acanthopanax senticosus enhances intestinal integrity through inhibiting TLR4/ NF-kappaB signaling pathways in lipopolysaccharide-challenged mice. Animal Sci j. 2016;87(8):1011-1018. doi:10.1111/asj.12528

7. $\mathrm{Xu} \mathrm{H}$, Hao $\mathrm{S}$, Gan $\mathrm{F}$, et al. In vitro immune toxicity of ochratoxin A in porcine alveolar macrophages: a role for the ROS-relative TLR4/MyD88 signaling pathway. Chem Biol Interact. 2017;272:107-116. doi:10.1016/j.cbi.2017.05.016

8. Wang W, Hu X, Shen P, Zhang N, Fu Y. Sodium houttuyfonate inhibits LPS-induced inflammatory response via suppressing TLR4/ NF-kB signaling pathway in bovine mammary epithelial cells. Microb Pathog. 2017;107:12-16. doi:10.1016/j.micpath.2017.03.011

9. Yao C, Narumiya S. Prostaglandin-cytokine crosstalk in chronic inflammation. Br J Pharmacol. 2019;176(3):337-354. doi:10.1111/ bph. 14530

10. Zhao XJ, Yu HW, Yang YZ, et al. Polydatin prevents fructose-induced liver inflammation and lipid deposition through increasing miR-200a to regulate Keap1/Nrf2 pathway. Redox Biol. 2018;18:124-137. doi:10.1016/j.redox.2018.07.002

11. Lv H, Yu Z, Zheng Y, et al. Isovitexin exerts anti-inflammatory and anti-oxidant activities on lipopolysaccharide-induced acute lung injury by inhibiting MAPK and NF-kappaB and Activating $\mathrm{HO}-1 / \mathrm{Nrf} 2$ Pathways. Int J Biol Sci. 2016;12(1):72-86. doi:10.7150/ijbs.13188

12. Menon D, Coll R, O’Neill LA, Board PG. Glutathione transferase omega 1 is required for the lipopolysaccharide-stimulated induction of NADPH oxidase 1 and the production of reactive oxygen species in macrophages. Free Radic Biol Med. 2014;73:318-327. doi:10.1016/j.freeradbiomed.2014.05.020

13. Lv H, Liu Q, Wen Z, Feng H, Deng X, Ci X. Xanthohumol ameliorates lipopolysaccharide (LPS)-induced acute lung injury via induction of AMPK/GSK3beta-Nrf2 signal axis. Redox Biol. 2017;12:311-324. doi:10.1016/j.redox.2017.03.001

14. Sahu BD, Kumar JM, Sistla R. Fisetin, a dietary flavonoid, ameliorates experimental colitis in mice: relevance of NF-kappaB signaling. J Nutr Biochem. 2016;28:171-182. doi:10.1016/j. jnutbio.2015.10.004 
15. Sajadimajd S, Bahramsoltani R, Iranpanah A, et al. Advances on natural polyphenols as anticancer agents for skin cancer. Pharmacolo Res. 2020;151:104584. doi:10.1016/j.phrs.2019.104584

16. Zheng W, Feng Z, You S, et al. Fisetin inhibits IL-1beta-induced inflammatory response in human osteoarthritis chondrocytes through activating SIRT1 and attenuates the progression of osteoarthritis in mice. Int Immunopharmacol. 2017;45:135-147. doi:10.1016/j. intimp.2017.02.009

17. Noh EM, Park YJ, Kim JM, et al. Fisetin regulates TPA-induced breast cell invasion by suppressing matrix metalloproteinase-9 activation via the PKC/ROS/MAPK pathways. Eur J Pharmacol. 2015;764:79-86. doi:10.1016/j.ejphar.2015.06.038

18. Kim S, Choi KJ, Cho SJ, et al. Fisetin stimulates autophagic degradation of phosphorylated tau via the activation of TFEB and Nrf2 transcription factors. Sci Rep. 2016;6:24933. doi:10.1038/srep24933

19. Geraets L, Haegens A, Brauers K, et al. Inhibition of LPS-induced pulmonary inflammation by specific flavonoids. Biochem Biophys Res Commun. 2009;382(3):598-603. doi:10.1016/j.bbrc.2009.03.071

20. Healy LL, Cronin JG, Sheldon IM. Polarized epithelial cells secrete interleukin 6 apically in the bovine endometrium. Biol Reprod. 2015;92(6):151. doi:10.1095/biolreprod.115.127936

21. Wu H, Zhao G, Jiang K, Li C, Qiu C, Deng G. Engeletin alleviates lipopolysaccharide-induced endometritis in mice by inhibiting TLR4mediated NF-кB Activation. J Agric Food Chem. 2016;64 (31):6171-6178. doi:10.1021/acs.jafc.6b02304

22. Wu H, Jiang K, Zhang T, Zhao G, Deng G. Hydroxytyrosol exerts an anti-inflammatory effect by suppressing Toll-like receptor 2 and TLR 2 downstream pathways in Staphylococcus aureus -induced mastitis in mice. $J$ Funct Foods. 2017;35:595-604. doi:10.1016/j. jff.2017.06.035

23. Wu H, Zhao G, Jiang $\mathrm{K}$, et al. Plantamajoside ameliorates lipopolysaccharide-induced acute lung injury via suppressing NF-kappaB and MAPK activation. Int Immunopharmacol. 2016;35:315-322. doi:10.1016/j.intimp.2016.04.013

24. Frazier-Jessen MR, Thompson CD, Brown R, Rawat R, Nordan RP, Feldman GM. NF- $\mathrm{BB}$ elements contribute to junB inducibility by lipopolysaccharide in the murine macrophage cell line RAW264.7. FEBS Lett. 2002;513(2-3):203-207. doi:10.1016/S0014-5793(02) 02295-0

25. Lee TM, Lin SZ, Chang NC. Antiarrhythmic effect of lithium in rats after myocardial infarction by activation of Nrf2/HO-1 signaling. Free Radic Biol Med. 2014;77:71-81. doi:10.1016/j. freeradbiomed.2014.08.022

26. Ci X, Zhou J, Lv H, Yu Q, Peng L, Hua S. Betulin exhibits anti-inflammatory activity in LPS-stimulated macrophages and endotoxin-shocked mice through an AMPK/AKT/Nrf2-dependent mechanism. Cell Death Dis. 2017;8(5):e2798. doi:10.1038/ cddis.2017.39
27. Jadeja RN, Jones MA, Abdelrahman AA, et al. Inhibiting microRNA-144 potentiates Nrf2-dependent antioxidant signaling in RPE and protects against oxidative stress-induced outer retinal degeneration. Redox Biol. 2020;28:101336. doi:10.1016/j. redox.2019.101336

28. Wang P, Geng J, Gao J, et al. Macrophage achieves self-protection against oxidative stress-induced ageing through the Mst-Nrf2 axis. Nat Commun. 2019;10(1):755. doi:10.1038/s41467-019-08680-6

29. Currais A, Prior M, Dargusch R, et al. Modulation of p25 and inflammatory pathways by fisetin maintains cognitive function in Alzheimer's disease transgenic mice. Aging Cell. 2014;13 (2):379-390. doi:10.1111/acel.12185

30. Yousefzadeh MJ, Zhu Y, McGowan SJ, et al. Fisetin is a senotherapeutic that extends health and lifespan. EBioMedicine. 2018;36:18-28. doi:10.1016/j.ebiom.2018.09.015

31. Li Y, Cifuentes-Pagano E, DeVallance ER, et al. NADPH oxidase 2 inhibitors CPP11G and CPP11H attenuate endothelial cell inflammation \& vessel dysfunction and restore mouse hind-limb flow. Redox Biol. 2019;22:101143. doi:10.1016/j.redox.2019.101143

32. Kim DH, Kim ME, Lee JS. Inhibitory Effects of Extract from G. lanceolata on LPS-Induced Production of Nitric Oxide and IL-1 $\beta$ via Down-regulation of MAPK in Macrophages. Appl Biochem Biotechnol. 2015;175(2):657-665. doi:10.1007/s12010-014-1301-8

33. Murakami A, Ohigashi H. Targeting NOX, INOS and COX-2 in inflammatory cells: chemoprevention using food phytochemicals. Int $J$ Cancer. 2007;121(11):2357-2363. doi:10.1002/ijc.23161

34. Peng S, Hang N, Liu W, et al. Andrographolide sulfonate ameliorates lipopolysaccharide-induced acute lung injury in mice by downregulating MAPK and NF- $\mathrm{B}$ pathways. Acta Pharmaceutica Sinica B. 2016;6(3):205-211. doi:10.1016/j.apsb.2016.02.002

35. Liu Y, Zhang Q, Ding Y, et al. Histone lysine methyltransferase Ezh1 promotes TLR-triggered inflammatory cytokine production by suppressing Tollip. J Immunol. 2015;194(6):2838-2846. doi:10.4049/ jimmunol.1402087

36. Hayden MS, Ghosh S. Shared principles in NF-kappaB signaling. Cell. 2008;132(3):344-362. doi:10.1016/j.cell.2008.01.020

37. Dai Y, Zhang J, Xiang J, Li Y, Wu D, Xu J. Calcitriol inhibits ROSNLRP3-IL-1 $\beta$ signaling axis via activation of Nrf2-antioxidant signaling in hyperosmotic stress stimulated human corneal epithelial cells. Redox Biol. 2019;21:101093. doi:10.1016/j.redox.2018.101093

38. Abed DA, Goldstein M, Albanyan H, Jin H, Hu L. Discovery of direct inhibitors of Keap1-Nrf2 protein-protein interaction as potential therapeutic and preventive agents. Acta Pharmaceutica Sinica B. 2015;5(4):285-299. doi:10.1016/j.apsb.2015.05.008
Journal of Inflammation Research

\section{Publish your work in this journal}

The Journal of Inflammation Research is an international, peerreviewed open-access journal that welcomes laboratory and clinical findings on the molecular basis, cell biology and pharmacology of inflammation including original research, reviews, symposium reports, hypothesis formation and commentaries on: acute/chronic inflammation; mediators of inflammation; cellular processes; molecular mechanisms; pharmacology and novel anti-inflammatory drugs; clinical conditions involving inflammation. The manuscript management system is completely online and includes a very quick and fair peerreview system. Visit http://www.dovepress.com/testimonials.php to read real quotes from published authors. 